\title{
EVALUASI PROGRAM POSYANDU LANSIA DI WILAYAH KERJA PUSKESMAS HARAPAN RAYA KEC. BUKIT RAYA KOTA PEKANBARU TAHUN 2019
}

\author{
Muhammad Dedi Widodo ${ }^{1}$, Leon Candra ${ }^{2}$, Elfia Elmasefira ${ }^{3}$ \\ Program Studi Kesehatan Masyarakat \\ STIKes Hang Tuah Pekanbaru \\ dediwidodo89@gmail.com ${ }^{1}$, leoncandraARS@yahoo.com²
}

\begin{abstract}
Implementation of the health service post elderly Harapan Raya Public Health Center not maximum this because lack of human resources, limited budgets, facilities and infrastructure that are not available, and the lack of the elderly in utilizing the integrated of the health service post elderly. The purpose of this research is to Evaluation of Elderly Integrated Service Post Program in the Working Area of Harapan Raya Public Health Center, Bukit Raya City, Pekanbaru District. This study used a qualitative with a qualitative descriptive design with in-depth interview method and observation of 10 informants consisting of program managers in the elderly, nurses, elderly post service cadres, and the elderly. This research was conducted in June 2019 at the Elderly Post Service in the Working Area of Harapan Raya Public Health Center in Bukit Raya City, Pekanbaru. The results of this study state that the availability of human resources is quite adequate, the financing of integrated service posts for the elderly is not sufficient, the availability of facilities and infrastructure is inadequate, the policy is in line with Law No. 36 of 2009 concerning Health Article 138, the implementation of integrated service posts for the elderly has not been optimal. It is recommended that the Harapan Raya Public Health Center to provide guidance and skills to all cadres, improve cooperation with community leaders to get material support, facilities and infrastructure, follow and adjust to the policies that have been set.
\end{abstract}

Keywords : Financing, Facilities, Human Resources, Implmentation, and Policy

\begin{abstract}
ABSTRAK
Pelaksanaan posyandu lansia Puskesmas Harapan Raya belum maksimal, dikarenakan kurangnya sumber daya manusia, keterbatasan anggaran, sarana dan prasarana yang belum tersedia dengan lengkap, dan kurangnya minat lansia dalam memanfaatkan kegiata posyandu lansia. Penelitian ini bertujuan untuk mengetahui Evaluasi Program Posyandu Lansia di Wilayah Kerja Puskesmas Harapan Raya Kecamatan Bukit Raya Kota Pekanbaru. Jenis penelitian ini adalah kualitatif dengan desain deskriptif kualitatif dengan metode wawancara mendalam dan observasi 10 orang informan terdiri dari penanggung jawab program lansia, perawat, kader posyandu lansia, dan lansia. Penelitian ini dilaksanakan pada bulan Juni 2019 di Posyandu Lansia Wilayah Kerja Puskesmas Harapan Raya Kecamatan Bukit Raya Kota Pekanbaru. Hasil penelitian ini menyatakan ketersediaan sumber daya manusia cukup memadai, pembiayaan posyandu lansia belum memadai, ketersediaan sarana dan prasarana belum memadai kebijakan sudah sejalan dengan Undang-Undang No. 36 Tahun 2009 tentang Kesehatan pasal 138, pelaksanaan posyandu lansia belum optimal. Disarankan Puskesmas Harapan Raya untuk melakukan pembinaan dan keterampilan pada semua kader, meningkatkan kerjasama dengan tokoh masyarakat agar mendapat dukungan materil, sarana dan prasarana, mengikuti dan menyesuaikan dengan kebijakan yang telah ditetapkan.
\end{abstract}

Kata Kunci : Kebijakan, Pembiayaan, Sarana dan Prasarana, Posyandu Lansia, dan Sumber Daya Manusia

\section{PENDAHULUAN}

Salah satu upaya meningkatkan derajat kesehatan dan mutu kehidupan lansia untuk mencapai masa tua yang bahagia dan berdaya guna dalam kehidupan berkeluarga dan masyarakat sesuai dengan meningkatkan kesadaran para lansia untuk membina sendiri kesehatannya, 
meningkatkan kemampuan dan peran serta keluarga dan masyarakat dalam mengatasi kesehatan lansia, meningkatkan jenis dan jangkauan pelayanan kesehatan lansia serta mutu pelayanan kesehatan. Hal ini dapat dilaksanakan di Pelayanan Posyandu Lanjut Usia, yang merupakan wadah pelayanan kepada lansia di masyarakat, yang proses pembentukan dan pelaksanaannya dilakukan oleh masyarakat bersama Lembaga Swadaya Masyarakat (LSM), lintas sektor pemerintah dan nonpemerintah, swasta, organisasi sosial, dan lain-lain yang menitikberatkan pada pelayanan promotif, preventif, tanpa mengabaikan upaya kuratif dan rehabilitatif (Notoatmodjo, 2012).

Posyandu lansia di Indonesia dilaksanakan berdasarkan Peraturan Perundang-Undangan sebagai landasan dalam menentukan kebijaksanaan pembinaan sesuai dengan Undang-Undang RI No. 13 Tahun 1998 tentang Kesejahteraan Lanjut Usia yang menyebutkan bahwa pelayanan kesehatan dimaksudkan untuk memelihara dan meningkatkan derajat kesehatan dan kemampuan lansia, upaya penyuluhan, penyembuhan dan pengembangan lembaga (Kominas Lansia, 2010).

Hasil penelitian Yulanda (2017) dalam Pelaksanaan Posyandu Lansia Desa Kotabaru Seberida Wilayah Kerja Puskesmas Kotabaru Kecamatan Keritang Kabupaten Indragiri Hilir, mengatakan yaitu sumber daya manusia sudah cukup memadai, kebijakan posyandu lansia sudah ada dari Dinas Kesehatan, sarana dan prasarana untuk pelaksanaan posyandu lansia belum tersedia dengan lengkap, pembiayaan untuk pelaksanaan posyandu lansia belum memadai, belum ada alokasi dana khusus kegiatan posyandu lansia, dan pelaksanaan posyandu lansia belum terlaksana secara rutin setiap bulan.

Secara global United Nations (PBB) telah memprediksi pertambahan lansia hingga 2,6\%. Pertambahan jumlah ini melebihi pertambahan populasi keseluruhan yaitu $(1,2 \%)$. Jumlah lansia meningkat menjadi 700 Juta di tahun 2009 dan diproyeksikan di tahun 2050 mencapai 2 milyar, 3 kali lebih tinggi dibandingkan yang terjadi di tahun 2009 (Mengko, et.al, 2015).

Berdasarkan Pusdatin Lansia 2017, jumlah lansia di Indonesia diperkirakan terdapat 23,66 juta jiwa, setara dengan 9,03\% dari seluruh penduduk Indonesia tahun 2017. Diprediksi jumlah penduduk lansia tahun 2020 adalah 27,08 juta jiwa, tahun 202533,69 juta jiwa, dan tahun 2030 terdapat 40,95 juta jiwa (Kemenkes RI, 2017).

Pada tahun 2016 sebanyak 56.104 lansia $(68,58 \%)$ dari jumlah keseluruhan 92.619 lansia mendapat pelayanan kesehatan. Sedangkan pada tahun 2017 sebanyak 7.849 lansia dari jumlah keseluruhan 52.460 lansia mendapat pelayanan kesehatan sebanyak $14,96 \%$ dari seluruh lansia yang ada. Ini berarti terjadi penurunan persentase pelayanan kesehatan terhadap lansia selama tahun 2017. Hal ini dikarenakan pada tahun ini disesuaikan dengan Pelaksanaan Posyandu Lansia bahwa yang terdata adalah lansia yang benar-benar melaksanakan skrining kesehatan (Profil Dinas Kesehatan Kota Pekanbaru, 2017).

Pada tahun 2018 penduduk lansia yang mendapat pelayanan kesehatan sebanyak 1.432 orang $(45,3 \%)$ dari 3.163 orang lansia. Sedangkan Jumlah kunjungan lansia di Posyandu lansia Puskesmas Harapan Raya masih rendah yaitu 28\% dari target program $75 \%$ dengan jumlah lansia 3.163 orang (Profil Puskesmas Harapan Raya, 2018).

Berdasarkan survei awal di 3 Puskesmas di Kota Pekanbaru, yaitu Puskesmas Garuda, Puskesmas Sapta Taruna, dan Puskesmas Harapan Raya. Pada 2 Puskesmas yang telah dilakukan survei, kunjungan posyandu lansia nya sudah mencapai target. Sedangkan di Puskesmas Harapan Raya merupakan Puskesmas yang memiliki jumlah lansia terbanyak tetapi dengan jumlah kunjungan lansia terendah 
dalam pemanfaatan Posyandu yaitu dengan cakupan $28 \%$.

Berdasarkan hasil wawancara dan observasi kepada penanggung jawab program yang peneliti lakukan di Puskesmas Harapan Raya mengenai posyandu lansia, bahwa 4 posyandu lansia yang ada di wilayah kerja Puskesmas Harapan Raya kunjungan lansianya masih rendah. Secara garis besar masalah yang dihadapi dari program posyandu lansia antara lain kurangnya Sumber Daya Manusia dalam pelaksanaan Posyandu sehingga kader memiliki peran ganda, keterbatasan anggaran seperti uang jasa tenaga kesehatan dan kader, sarana dan prasarana yang belum tersedia dengan lengkap seperti alat pemeriksaan gula darah, kolestrol, dan asam urat serta belum adanya tempat khusus untuk pelaksanaan posyandu lansia karena sampai saat ini masih bergabung dengan posyandu balita dan hari pelaksanaan yang bersamaan, mekanisme 5 meja yang belum berjalan.Tujuan dari penelitian ini adalah untuk mengetahui Evaluasi Program Posyandu Lansia di Wilayah Kerja Puskesmas Harapan Raya Kecamatan Bukit Raya Kota Pekanbaru.

\section{METODE}

Jenis penelitian yang digunakan dalam penelitian ini adalah kualitatif dengan desain deskriptif kualitatif dilakukan di empat posyandu lansia yang ada di wilayah kerja Puskesmas Harapan Raya Kecamatan Bukit Raya Kota Pekanbaru. Waktu penelitian ini dilakukan pada bulan Juli 2019. Subjek dipilih sesuai dengan prinsip kesesuaian dan kecukupan, dimana kriteria informan yang dipilih dalam penelitian ini bersedia diwawancarai, mengetahui permasalahan dengan jelas dan dapat dipercaya untuk menjadi sumber data yang baik. Subjek penelitian ini yaitu, pemegang program lansia 1 orang, perawat pelaksana posyandu lansia 1 orang, kader 4 orang, dan lansia 4 orang.

\section{HASIL}

\section{Sumber Daya Manusia}

Berdasarkan hasil penelitian yang dilakukan melalui wawancara mendalam dengan informan terkait sumber daya manusia dalam penelitian ini adalah pelaksana posyandu lansia yang terdiri dari kader serta tenaga kesehatan dari Puskesmas dengan melihat aspek ketersediaan serta karakteristik sumber daya manusia yang meliputi tingkat pendidikan serta dilihat dari pendidikan dan pelatihan. Jumlah kader keempat posyandu lansia adalah berjumlah 20 orang yang dipilih oleh Ibu PKK untuk perwakilan dari masingmasing RT. Jumlah kader di keempat posyandu lansia sudah sesuai dengan yang dianjurkan dalam pedoman pelaksanaan posyandu lansia dimana setiap posyandu minimal harus terdapat 5 orang kader. Akan tetapi, setelah dilakukan wawancara dengan kader posyandu lansia Anggrek 7 dan Anggrek 9 jumlah kader yang aktif di masing-masing posyandu adalah 2 orang. Namun demikian, dalam pelaksanaannya posyandu lansia tetap berjalan tetapi dengan adanya kekurangan kader maka dapat konsekuensi tugas kader menjadi rangkap. Upaya yang telah dilakukan penanggung jawab program lansia dan ketua kader untuk mendapatkan kader pengganti, masyarakat tidak ada yang mau menjadi kader dengan alasan banyak pekerjaan dirumah dan tanggung jawab kader yang banyak.

Selanjutnya karakteristik kader yang dilihat dari rata-rata pendidikan terakhir kader posyandu lansia di wilayah kerja Puskesmas Harapan Raya adalah minimal SMA dan maksimal D3.

Upaya yang telah dilakukan penanggung jawab program lansia dan ketua kader untuk mendapatkan kader pengganti, masyarakat tidak ada yang mau menjadi kader dengan alasan banyak pekerjaan dirumah dan tanggung jawab kader yang banyak. Selain itu, perlu adanya pelatihan bagi semua kader posyandu. Padahal pada dasarnya sangat perlu dilakukan upaya pengembangan dan 
pelatihan terhadap semua kader posyandu lansia, agar posyandu lansia dapat terlaksana dengan baik dan sesuai dengan standar kegiatan yang telah ditetapkan.

Berdasarkan hasil observasi yang dilakukan peneliti terhadap informan didapatkan bahwa tenaga kesehatan yang ada di puskesmas harapan raya sudah mendukung pelaksanaan kegiatan posyandu lansia. Hal ini dapat dibuktikan dengan petugas kesehatan dan kader posyandu lansia selalu ada pada waktu pelaksanaan posyandu lansia berlangsung, serta petugas selalu mencatat dan melakukan pendataan setiap kali melakukan posyandu lansia.

\section{Pembiayaan}

Berdasarkan hasil penelitian yang dilakukan melalui wawancara mendalam dengan informan terkait pembiayaan posyandu lansia Anggrek 1, Harum Sari, Anggrek 7 dan Anggrek 9 Puskesmas Harapan Raya Kecamatan Bukit Raya Kota Pekanbaru dengan melihat aspek ketersediaan dan kecukupannya ditemukan bahwa pembiayaan untuk pelaksanaan posyandu lansia bersumber dari swadaya masyarakat dengan mekanisme iuran rutin yang diberikan pada pelaksanaan posyandu maupun saat acara wirid lansia. Sedangkan pemerintah kota maupun puskesmas hanya memberikan bantuan berupa stik untuk pengecekan gula darah, kolestrol, dan asam urat. Pembiayaan untuk pelaksanaan posyandu lansia dirasa masih belum mencukupi dan belum adanya dana khusus untuk pelaksanaan posyandu lansia di keempat posyandu lansia wilayah kerja Puskesmas Harapan Raya. Padahal kegiatan tersebut memerlukan biaya yang besar. Hal ini dapat dilihat dari masih kurangnya alat kesehatan, biaya untuk jasa petugas dan kader serta biaya untuk Pemberian Makanan Tambahan (PMT).

\section{Ketersediaan Sarana dan Prasarana}

Berdasarkan hasil penelitian yang dilakukan melalui wawancara mendalam dengan informan terkait sarana dan prasarana di posyandu lansia Anggrek 1,
Harum Sari, Anggrek 7 dan Anggrek 9 di Wilayah Kerja Puskesmas Harapan Raya Kecamatan Bukit Raya Kota Pekanbaru dengan melihat ketersediaan dan kelayakan. Mengacu pada pedoman pelaksanaan posyandu lansia, sarana dan prasarana meliputi ruangan; formulir registrasi lansia, alat pengukur tinggi badan, penimbangan berat badan, alat pengukur tekanan darah, gula darah, dan hemoglobin; PMT; dan formulir pencatatan ditemukan bahwa sarana dan prasarana yang ada pada keempat posyandu lansia belum lengkap, karena masih terdapat kekurangan.

Berdasarkan hasil observasi yang dilakukan, sarana dan prasarana yang ada di keempat posyandu lansia dari segi alat kesehatannya sudah cukup baik. Hal ini terlihat dari tersedianya alat timbangan, tensimeter, alat pemeriksaan gula darah, kolestrol dan asam urat. Akan tetapi, untuk tempat pelaksanaan kegiatan posyandu lansia belum memadai dikarenakan masih bergabung dengan posyandu balita. Serta PMT tidak selalu disediakan dengan alasan keterbatasan anggaran.

Ditemukan bahwa keempat sarana dan prasarana yang ada pada posyandu lansia masih belum lengkap, karena masih terdapat beberapa kekurangan. Hal ini dapat dilihat belum adanya tempat khusus posyandu lansia serta belum ada daya tarik yang dibuat oleh petugas untuk menumbuhkan minat lansia untuk mengikuti kegiatan posyandu lansia.

Pada aspek kelayakan didapatkan pula informasi dari dua informan yang menyatakan bahwa alat pengecekan gula darah, kolestrol dan asam urat mengalami kerusakan pada satu bulan terakhir. Informan lainnya menyatakan bahwa tidak terdapat pengukuran tinggi badan dan pengukuran lingkar lengan.

\section{Kebijakan}

Berdasarkan hasil penelitian yang dilakukan melalui wawancara mendalam dengan informan terkait kebijakan pelaksanaan kegiatan posyandu lansia di wilayah kerja puskesmas harapan raya 
kecamatan bukit raya sudah cukup baik. Kebijakan pelaksanaan posyandu lansia sudah sesuai dengan Undang-Undang No. 36 Tahun 2009 pasal 138 tentang Kesehatan.

Disebutkan dalam Undang-Undang No. 36 pasal 138 tentang kesehatan bahwa upaya pemeliharaan kesehatan bagi lanjut usia harus ditujukan untuk menjaga agar tetap hidup sehat dan produktif secara sosial maupun ekonomis sesuai dengan martabat kemanusiaan. Pemerintah wajib menjamin ketersediaan fasilitas pelayanan kesehatan dan memfasilitasi kelompok lanjut usia untuk dapat tetap hidup mandiri dan produktif secara sosial dan ekonomis.

\section{Pelaksanaan}

Berdasarkan hasil penelitian yang dilakukan melalui wawancara mendalam dengan informan terkait pelaksanaan posyandu lansia Anggrek 1, Harum Sari, Anggrek 7 dan Anggrek 9 Puskesmas Harapan Raya Kecamatan Bukit Raya Kota Pekanbaru ditemukan bahwa pelaksanaan program posyandu lansia belum berjalan efektif dikarenakan masih adanya lansia yang tidak hadir dalam pelaksanaan kegiatan posyandu lansia berlangsung karena kurangnya minat lansia ke posyandu, jarak pelayanan yang jauh, belum ada tempat khusus untuk pelaksanaannya posyandu dan belum ada KMS dan PMT untuk lansia dan belum berjalannya sistem 5 meja.

\section{PEMBAHASAN}

\section{Sumber Daya Manusia}

Menurut Meisari (2017) sumber daya manusia adalah human resoures atau manpower yang memiliki perasaan, keinginan, keterampiran, pengetahuan yang sangat berpengaruh terhadap upaya organisasi dalam mencapai tujuan. Sumber Daya Manusia (SDM) juga merupakan modal yang dimiliki oleh organisasi yang harus dikelola secara efektif untuk mampu memberikan persepsi baik terhadap organisasi.
Penelitian ini juga sejalan dengan penelitian yang dilakukan Yulanda (2017) di Puskesmas Kotabaru yang menyatakan bahwa sumber daya manusia yang ada di puskesmas sudah cukup memadai, hanya saja sumber daya manusia yang ada belum dilakukan upaya pengembangan dan pelatihan agar lebih terampil lagi.

Berdasarkan hasil penelitian dan teori yang relevan maka peneliti berpendapat bahwa sumber daya manusia merupakan faktor terpenting dalam suatu organisasi yang sangat tergantung pada sumber daya manusia yang ada didalamnya, karena sumber daya manusia merupakan faktor penggerak yang utama dalam berjalannya tugas tersebut. Sumber daya manusia sudah cukup memadai hanya saja terdapat dua posyandu yang memiliki tugas rangkap. Akan tetapi masih ada kendala mengenai belum adanya pelatihan bagi semua kader pelaksana posyandu lansia. Oleh karena itu, agar tercapai pelaksanaan posyandu lansia yang maksimal di wilayah kerja puskesmas harapan raya, sebaiknya pihak puskesmas mengadakan pelatihan keterampilan terhadap kader posyandu lansia.

\section{Pembiayaan}

Menurut Alamsyah (2012) untuk melakukan aktivis membutuhkan uang, seperti upah atau gaji manusia yang melakukan perencanaan, mengadakan pengawasan. Uang sebagai sarana manajemen harus digunakan sedemikian rupa agar tujuan yang ingin dicapai bila dinilai dengan uang yang lebih besar dari uang yang digunakan untuk mencapai tujuan tersebut.

Penelitian ini sejalan dengan Yulanda (2017) di wilayah keja Puskesmas Kotabaru pembiayaan belum memadai karena tidak terdapat alokasi dana khusus untuk menjalankan kegiatan posyandu lansia, hanya saja dalam pelaksanaannya dana yang digunakan diambil dari dana BOK (Bantuan Operasional Kesehatan). Akan tetapi dana tersebut belum cukup untuk melaksanakan kegiatan posyandu lansia secara rutin setiap bulan. 
Berdasarkan hasil penelitian dan teori yang relevan maka peneliti berasumsi bahwa adanya keterbatasan anggaran sehingga pelaksanaan kegiatan posyandu lansia tidak berjalan optimal. Sebaiknya untuk mengatasi keterbatasan anggaran dalam pelaksanaan posyandu lansia perlu diupayakan donatur tetap atau kerjasama lintas sektor untuk kegiatan posyandu lansia.

\section{Ketersediaan Sarana dan Prasarana}

Menurut Ismawati (2011) agar posyandu lansia terlaksana dan berjalan secara efektif diperlukan sarana dan prasarana penunjang, seperti kegiatan (gedung, ruangan atau tempat terbuka), meja dan kursi, alat tulis, buku pencatatan kegiatan, timbangan, meteran pengukuran tinggi badan, stetoskop, tensi meter, peralatan laboratorium sederhana, termometer, serta Kartu Menuju Sehat (KMS) lansia.

Penelitian ini sejalan dengan penelitian Anugerah (2015) di Kecamatan Medan Deli menyatakan bahwa sarana dan prasarana yang ada dalam pelaksanaan posyandu lansia belum mencukupi dan tidak tersedia secara merata, sehingga kegiatannya belum dapat berjalan dengan baik. Disalah satu posyandu lansia yang ada di Kelurahan Mabar, alat-alat untuk pemeriksaan gula, kolestrol dan asam urat belum ada tersedia, sedangkan posyandu di Kelurahan Mabar Hilir alat-alat tersebut sudah tersedia dan dibawa oleh petugas puskesmas dan itu harus mengeluarkan biaya untuk melakukan pemeriksaan misalnya gula, kolestrol dan asam urat. Pihak puskesmas seharusnya dalam pengadaan alat-alat untuk pemeriksaan tersebut harus dibuat secara merata agar lansia tersebut mau datang ke posyandu dan dapat memantau kesehatannya.

Berdasarkan hasil penelitian dan teori yang relevan maka peneliti berasumsi bahwa pelaksanaan posyandu lansia tentunya memerlukan sarana dan prasarana yang lengkap agar kegiatan dapat berjalan optimal. Karena sarana dan prasarana merupakan faktor penting agar kegiatan posyandu lansia berjalan dengan baik.

\section{Kebijakan}

Menurut Mustopadidjaja kebijakan adalah keputusan suatu organisasi yang dimaksudkan untuk mengatasi permasalahan tertentu sebagai keputusan atau untuk mencapai tujuan tertentu, berisikan ketentuan-ketentuan yang dapat dijadikan pedoman perilaku.

Penelitian ini sesuai dengan penelitian Idris (2015) di Puskesmas Tambang Kabupaten Kampar dimana hasil penelitiannya juga menunjukkan bahwa kebijakan tentang kegiatan program usia lanjut sudah cukup baik, namun dalam realisasi kebijakannya kurang maksimal dikarenakan sarana dan pendanaan belum memadai. Hal ini menyebabkan pelaksanaan kegiatan usia lanjut tidak terlaksana dengan baik.

Berdasarkan hasil penelitian dan teori yang relevan maka peneliti berpendapat bahwa kebijakan tentang posyandu lansia sudah sesuai, namun pelaksanaannya belum berjalan optimal oleh karena itu sebaiknya pelaksanaan kebijakan juga harus di dukung oleh pelaksanaan tentang tenaga kesehatan puskesmas dan kader serta dukungan oleh sarana dan prasarana seperti alat kesehatan dan gedung khusus untuk posyandu lansia dan anggaran khusus agar terlaksanya pelaksanaan kebijakan tentang posyandu lansia.

\section{Pelaksanaan}

Pelaksanaan adalah suatu tindakan yang mengusahakan menggerakkan dan mengarahkan pelaksanaan program dengan cara menciptakan iklim kerjasama antara pegawai pelaksanaan program sehingga pelaksanaan program berjalan sesuai dengan rencana dalam rangka pencapaian tujuan (Sulaiman, 2011).

Penelitian ini sejalan dengan penelitian Yulanda (2017) di Desa Kotabaru belum dilakukan secara optimal dan masih terdapat kendala dalam pelaksanaannya, mulai dari kegiatan yang tidak rutin setiap 
bulannya, kurangnya minat lansia ke posyandu, jarak pelayanan yang jauh, belum ada tempat khusus untuk pelaksanaan posyandu dan belum ada KMS untuk lansia. Secara garis besar kendala dalam pelaksanaannya posyandu lansia Desa Kotabaru Seberida Wilayah Kerja Puskesmas Kotabaru adalah kurangnya dana khusus untuk posyandu lansia.

Berdasarkan hasil penelitian dan teori yang relevan maka peneliti berpendapat bahwa pelaksanaan merupakan alur proses untuk menjalankan suatu program agar dapat berjalan dengan baik dan tercapai suatu tujuan yang diinginkan. Sehingga perlu adanya pembiayaan khusus untuk pelaksanaan posyandu lansia karena apabila terdapat kekurangan anggaran maka mengakibatkan suatu kegiatan tidak berjalan secara baik.

Untuk meningkatkan minat dan antusias lansia dalam pemanfaatan posyandu lansia dapat dicapai dengan pemberian reward secara langsung kepada lansia. Mengenai pentingnya kesehatan di usia lanjut serta diadakannya kegiatan yang lain seperti TOGA dan keterampilan.

\section{KESIMPULAN}

Berdasarkan hasil penelitian dan pembahasan yang peneliti uraikan tentang Evaluasi Program Posyandu Lansia di Wilayah Kerja Puskesmas Harapan Raya Kecamatan Bukit Raya Kota Pekanbaru Tahun 2019, sebagai berikut Ketersediaan Sumber Daya Manusia pada Program Posyandu Lansia di Wilayah Kerja Puskesmas Harapan Raya Kecamatan Bukit Raya Kota Pekanbaru sudah cukup memadai pada pelaksanaan kegiatan posyandu lansia. Hanya saja Sumber Daya Manusia belum semuanya mendapatkan pelatihan agar lebih terampil lagi dan bisa memotivasi lansia untuk datang dan memanfaatkan posyandu lansia. Ketersediaan Sarana dan prasarana pada Program Posyandu Lansia di Wilayah Kerja Puskesmas Harapan Raya Kecamatan Bukit Raya Kota Pekanbaru belum memadai karena masih terbatasnya alat kesehatan seperti tidak adanya pengukur tinggi badan, thermometer, KMS, serta tempat yang digunakan untuk kegiatan posyandu lansia masih bergabung dengan balita. Pembiayaan pada Program Posyandu Lansia di Wilayah Kerja Puskesmas Harapan Raya Kecamatan Bukit Raya Kota Pekanbaru belum memadai karena belum adanya alokasi dana khusus untuk menjalankan program, sehingga dalam pelaksanaannya hanya menggunakan uang swadaya masyarakat dan dana tersebut juga belum cukup untuk melaksanakan kegiatan posyandu lansia. Kebijakan pada Program Posyandu Lansia di Wilayah Kerja Puskesmas Harapan Raya Kecamatan Bukit Raya Kota Pekanbaru sudah sejalan dengan Undang-Undang No. 36 Tahun 2009 tentang Kesehatan pasal 138. Namun dalam penerapannya belum terlaksana dengan optimal dikarenakan oleh sarana dan prasarana serta pembiayaan yang masih terbatas.

Pelaksanaan pada Program Posyandu Lansia di Wilayah Kerja Puskesmas Harapan Raya Kecamatan Bukit Raya Kota Pekanbaru belum optimal pelaksanaannya. Mulai dari kurangnya minat lansia dalam pemanfaatan posyandu lansia, belum adanya tempat khusus untuk kegiatan posyandu lansia, belum adanya KMS untuk lansia.

\section{DAFTAR PUSTAKA}

\section{Report}

Dinas Kesehatan Kota Pekanbaru. (2017). Profil Dinas Kesehatan Kota Pekanbaru. Pekanbaru.

Profil Puskesmas Harapan Raya Tahun 2018.

\section{Journal}

Indarwati, Kustanti, \& Dayaningsih, S. (2017). Studi Pemanfaatan Posyandu Lansia dan Evaluasi Penggunaan KMS di Sukoharjo. Jurnal Profesi, Volume 15(1), 44-50. 
Melita, \& Nadjib, M. (2018). Faktor-Faktor Yang Berhubungan Dengan Kunjungan Lansia Ke Posbindu Lansia Di Wilayah Kerja Puskesmas Kelurahan Bintara Kota Bekasi Tahun 2017. Jurnal Kebijakan Kesehatan Indonesia (JKKI), 7(4), 158-167.

Nilasari, M. G., \& Prabawati, I. (2014). Evaluasi Peraturan Daerah Kota Surabaya No 32014 tentang Kesejahteraan Lanjut Usia (Studi pada Posyandu Lansia Sekar Melati di RW II Kelurahan Baratjaya Kecamatan Gubeng Kota Surabaya). Jurnal Fisip Universitas Negeri Surabaya.

Sulaiman. (2016). Faktor-Faktor Yang Berhubungan Dengan Pemanfaatan Posyandu Lansia Di Wilayah Kerja Desa Sukaraya Kecamatan Pancur Batu. Jurnal Ilmiah Research Sains. Volume 2, NO 22 Juni 2016

Book

Alamsyah, D. (2012). Manajemen Pelayanan Kesehatan. Yogyakarta: Nuha Medika.

Azuar, A. (2010). Pengantar Administrasi Kesehatan (Edisi Ketiga). Jakarta: Bina Rupa Aksara.

Efandi. (2014). Posyandu Lansia Mewujudkan Lansia Sehat, Mandiri, \& Produktif. Jakarta: EGC.

Gunawan, I. (2016). Metode Penelitian Kualitatif Teori \& Praktik. Jakarta: Bumi Aksara.

Imron, A. (2002). Kebijaksanaan Pendidikan Di Indonesia. Jakarta: PT. Bumi Aksara.

Ismawati, S. C. (2010). Posyandu (Pos Pelayanan Terpadu) Dan Desa Siaga. Yogyakarta: Nuha Medika.
Notoatmodjo, S. (2010). Metodologi Penelitian Kesehatan. Jakarta: Rineka Cipta.

Notoatmodjo, S. (2012). Promosi Kesehatan dan Ilmu Perilaku, Jakarta: Rineka Cipta.

\section{Thesis, Desertation}

Meisari, E. (2017). Peningkatan Kualitas Sumber Daya Manusia Guna Penanggulangan Pengangguran Kota Bandar Lampung Dalam Perspektif Ekonomi Islam. UIN Raden Intan Lampung.

Yulanda, T. (2017). Pelaksanaan Posyandu Lansia Desa Kotabaru Seberida Wilayah Kerja Puskesmas Kota Baru Kecamatan Keritang Kabupaten Indra Giri Hilir Riau Tahun 2017. Skripsi. Program Studi Ilmu Kesehatan Masyarakat STIKes Hang Tuah Pekanbaru. Pekanbaru.

\section{Laws, Regulations, Ministerial Decrees}

Kemenkes, RI Nomor 128/MENKES/SK/II/2004, (2004). Kebijakan Dasar Pusat Kesehatan Masyarakat.

Kepres. (2004). Keputusan Presiden Nomor 52 Tahun 2004 Tentang Komisi Nasional Lanjut Usia. Jakrta: Keputusan Presiden.

Permenkes RI. (2014). Peraturan Menteri Kesehatan Republik Indonesia Nomor 75 Tahun 2014 Tentang Pusat Kesehatan Masyarakat. Jakarta: Menkes RI.

Permenkes RI. (2015). Peraturan Menteri Kesehatan Republik Indonesia Nomor 67 Tahun 2015 Tentang Penyelenggaraan Pelayanan 
Kesehatan Lanjut Usia Di Pusat Kesehatan Masyarakat. Jakarta: Menkes RI.

Permenkes RI. (2016). Peraturan Menteri Kesehatan Republik Indonesia Nomor 25 Tahun 2016 Tentang Rencana Aksi Nasional Kesehatan
Lanjut Usia Tahun 2016-2019. Jakarta: Menkes RI.

Perpres, RI (2004). Peraturan Pemerintah Republik Indonesia No. 43 Tahun 2004 Tentang Pelaksanaan Upaya Peningkatan Kesejahteraan Sosial Lanjut Usia. Jakarta: Menkes RI. 